\title{
Can urinary neutrophil gelatinase-associated lipocalin have a role in the early diagnosis of acute kidney injury after coronary artery bypass graft?
}

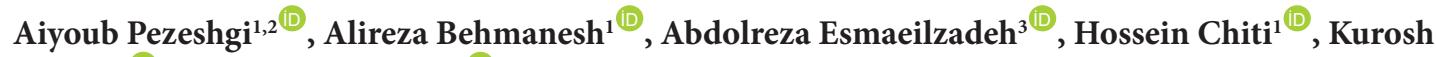 \\ Kamali $^{4}{ }^{\oplus}$, Mahrang Hedaiaty ${ }^{5^{*}} \mathbb{0}$ \\ ${ }^{1}$ Zanjan Metabolic Diseases Research Center, Zanjan University of Medical Sciences, Zanjan, Iran \\ ${ }^{2}$ Department of Internal Medicine, School of Medicine, Zanjan University of Medical Sciences, Zanjan, Iran \\ ${ }^{3}$ Department of Immunology, School of Medicine, Zanjan University of Medical Sciences, Zanjan, Iran \\ ${ }^{4}$ Department of Epidemiology, Zanjan University of Medical Sciences, Zanjan, Iran \\ ${ }^{5}$ Forensic Medicine- Legal Medicine Organization, Tehran, Iran
}

\section{A R T I C L E I N F O}

Article Type:

Original

\section{Article History:}

Received: 8 November 2019

Accepted: 13 January 2020

Published online: 5 February 2020

\section{Keywords:}

Coronary artery bypass graft, Acute kidney injury, Neutrophil gelatinase-associated lipocalin

\begin{abstract}
A B S T R A C T
Introduction: The role of urinary neutrophil gelatinase-associated lipocalin (NGAL) as a prognostic biomarker in acute kidney injury (AKI) associated with coronary bypass graft has been suggested in some studies. However, the results have been inconclusive in different studies.

Objectives: In the present research, we investigated the diagnostic and prognostic roles of NGAL in Iranian patients who developed AKI after coronary bypass surgery.

Patients and Methods: This study was cross-sectional conducted on adult patients undergoing coronary artery bypass graft (CABG) surgery. Postoperative AKI was defined based on the RIFLE (risk, injury, failure, loss and end-stage kidney disease) criteria. Patients were divided into AKI and non-AKI groups. The urinary NGAL and serum creatinine levels were measured at different times after surgery.

Results: Out of 29 patients, men constituted $75.9 \%$ of cases. Mean age of the patients was $61.4 \pm 7.7$ years old and the mean duration of surgery was $4.9 \pm 0.6$ hours. Based on serum creatinine, AKI was diagnosed in $37.9 \%, 17.25 \%$, and $13.8 \%$ of patients at first, second, and third day post-surgery, respectively. The urine NGAL increased by $48.35 \%$ and $34.5 \%$ at 2 and 6 hours after surgery, respectively. However, there was no significant association between the urinary NGAL level and the incidence of post-surgery AKI.

Conclusion: This study showed that urinary NGAL was inapplicable to independently diagnose or predict the outcome of transient AKI associated with CABG.
\end{abstract}

Implication for health policy/practice/research/medical education:

Urinary neutrophil gelatinase-associated lipocalin is not an independent diagnostic or prognostic biomarker in transient acute kidney injury associated with coronary artery bypass graft.

Please cite this paper as: Pezeshgi A, Behmanesh A, Esmaeilzadeh A, Chiti H, Kamali K, Hedaiaty M. Can urinary neutrophil gelatinase-associated lipocalin have a role in the early diagnosis of acute kidney injury after coronary artery bypass graft? J Renal Inj Prev. 2020; 9(2): e12. doi: 10.34172/jrip.2020.12.

\section{Introduction}

Coronary bypass graft is one of the most common surgeries worldwide. Transient acute kidney injury (AKI) is known as one of the major devastating complications of this surgical procedure. In addition to financial costs, AKI may lead to multi-organ dysfunctions and higher rate of mortality in this condition. The coronary artery bypass grafting (CABG) is annually conducted in around 1000000 patients (1) which up to $30 \%$ of them develop
AKI. About 3\% of the patients developing AKI following CABG will require dialysis, of whom more than $60 \%$ may be expired (2). The reported incidence of AKI after CABG varies based on the diagnostic criteria applied for this condition. The CABG-associated renal injury is generally defined as an increase in serum creatinine either $0.3 \mathrm{mg} / \mathrm{dL}(\geq 26.4 \mu \mathrm{mol} / \mathrm{L})$ or $50 \%$ of the baseline value (i.e. 1.5 folds from the baseline) within 48 hours postoperation (3). 
The risk factors of AKI following cardiopulmonary bypass surgery are generally related to a reduced renal perfusion and the blood supply. Based on such risk factors, scoring systems have been suggested to predict the prognosis of AKI $(4,5)$. However, these scoring systems have been mainly indicated in high-risk and hemodialysisdependent patients. In recent years, our understanding of the pathogenesis and therapeutic approaches of AKI has been improved by studies on animal models (6). On the other hand, most of the human studies have not resulted in successful treatment approaches (7). One of the important factors limiting the effectiveness of these therapeutic approaches is the lake of reliable diagnostic biomarkers to early diagnose of AKI which precludes advanced renal injury (8). In the current clinical practice, serum creatinine is the gold standard for diagnosis and classification of AKI (9). Nevertheless, serum creatinine level is not a reliable marker for monitoring the acute alternations in renal function $(7,8)$.

Neutrophil gelatinase-associated lipocalin (NGAL) belongs to the lipocalin genes superfamily and is produced by neutrophils, renal tubular, and epithelial cells in response to inflammation or renal tubular ischemic injury (8). The serum level of NGAL is low in conditions with normal renal function. On the other hand, urinary and plasma levels of NGAL are quickly increased in AKI. Therefore, it may be a useful biomarker to early diagnose this condition in patients undergoing kidney transplantation (10) as well as in hemolytic uremic syndrome (11), gentamycin induced renal damage (12), lupus nephritis (13) and contrast induced AKI (14). NGAL can be detected in urine samples approximately two hours after ischemia, and therefore can be a valuable predictor of AKI in clinical settings (15).

The role of NGAL as a diagnostic marker in AKI following the CABG is uncertain. Comprehensive knowledge on this issue can pave the way to early diagnose of $\mathrm{AKI}$ in this condition and to prevent its progression to end-stage kidney failure.

\section{Objectives}

Since the role of NGAL as a prognostic biomarker of AKI has been documented in numerous studies, the results have been inconclusive in different populations. Regarding the genetic diversity among populations, the present research aimed to assess the diagnostic validity of this biomarker in Iranian patients developing AKI after CABG.

\section{Patients and Method \\ Study population}

The present study was a cross-sectional research. The research population included all adult patients undergoing CABG surgery in Musavi hospital of Zanjan (Iran). The patients were enrolled in the study from December 2016 until May 2017.
Patients with clinical conditions that might affect renal function were excluded from the study. The exclusion criteria were history of renal or hepatic failure, acute or chronic pulmonary diseases, pulmonary artery hypertension, previous cardiac surgery, malignancies, infectious disease, massive proteinuria $(>3.5 \mathrm{~g} /$ day $)$, evidences of ongoing inflammation (e.g. leukocytosis), and preoperative treatment with steroids or nephrotoxic drugs (e.g. aminoglycoside).

The required clinical and demographic information was initially gathered. The demographic data (age and gender), as well as the history of cardiac surgery or myocardial infarction, diabetes, vascular or respiratory diseases, renal dysfunction, smoking and finally the type and intensity of coronary artery stenosis were recorded by a questionnaire. In addition, the duration of operation and anesthesia, hemodynamic parameters, urine output and the total volume of drainage were also recorded.

Blood samples were taken for measuring baseline serum creatinine level before the induction of anesthesia. Then serum creatinine levels were measured for three consecutive days. Additionally, spot urine samples were obtained preoperatively, and at 2 and 6 hours after the CABG procedure. The blood samples were immediately centrifuged at $\geq 400 \mathrm{RCF}$ (relative centrifugal force) for 5 minutes. Then, all the centrifuged samples were transferred to microtubes, appropriately labeled and stored at $-70^{\circ} \mathrm{C}$ till examination. Urinary NGAL level was measured by fluorescence-based immunoassay using a specific ELISA kit (Cristal Day Biotech Kit, China).

The postoperative AKI was diagnosed based on the RIFLE (risk, injury, failure, loss, end-stage kidney disease) criteria [i.e. either $25 \%$ (or higher) or $\geq 0.3 \mathrm{mg} / \mathrm{dL}$ increases in serum creatinine level within 48 hours, or urine volume $<0.5 \mathrm{~mL} / \mathrm{kg} / \mathrm{h}$ for 6 hours].

\section{Ethical issues}

The research followed the tenets of the Declaration of Helsinki. Informed consent was obtained from all the patients. This study was approved by the Ethics Committee of Zanjan University of Medical Sciences (IR.ZUMS. REC.1392.82). Accordingly, all the participants were informed about the objectives of the study and assured that their information will remain confidential.

\section{Data analysis}

The collected data were analyzed by SPSS 22 software using descriptive and analytical tests. Mean $\pm \mathrm{SD}$, frequency and percentage were used to present the data. To compare quantitative variables, independent samples, student t-test and repeated measures ANOVA were applied. Kolmogorov-Smirnov test was used for checking the normality of the variables. The $P$ value less than 0.05 was considered as statistically significant. 
Results

Among patients undergoing CABG procedure, 29 fulfilled the inclusion criteria and entered into the study.

Men comprised $75.9 \%$ of the subjects. The patients' mean age was $61.4 \pm 7.7$ (median; 61 , minimum; 49 , and maximum; 78) years. There was no significant difference between the mean age of men ( $61.1 \pm 8.8$ years) and women (62.6 \pm 4.2 years; $p=0.657)$. Overall, $27.6 \%$ and $75.9 \%$ of the patients had diabetes and hypertension respectively without evidence of renal dysfunction.

The mean duration of the surgery was $4.9 \pm .6$ (median; 5 , minimum; 4, and maximum; 6.5) hours. The mean serum creatinine level before the surgery was $1.19 \pm 0.21$ (median; 1, minimum; 0.8, and maximum; 1.7) $\mathrm{mg} / \mathrm{dL}$. Only, two patients (6.9\%) had a serum creatinine level $>1.5 \mathrm{mg} / \mathrm{dL}$. There was no significant correlation between serum creatinine level and the duration of surgery ( $p>$ 0.05 ). Table 1 shows the means of serum creatinine level at different times during the study.

Overall, AKI was identified in $44.8 \%$ of the participants. Based on serum creatinine values, AKI was diagnosed in $37.9 \%, 17.25 \%$, and $13.8 \%$ of the patients at the first, second and third days, post-surgery, respectively.

The urine NGAL level increased by $48.35 \%$ and $34.5 \%$ at 2 hours and 6 hours after surgery respectively. There was no significant difference in the urine NGAL levels before surgery, within 2 hours, and 6 hours after surgery (Table 2). There was no significant difference comparing the urine NGAL level between the patients who developed AKI after the surgery and those without post-surgery AKI at any time (Table 2). No significant association of at least one-unit increase in urine NGAL at any time after surgery with the incidence of AKI was observed (Table 3).

In patients who developed AKI, the urinary level of NGAL increased by averages of $53.8 \%$ and $45.5 \%$ at 2 and 6 hours after surgery, respectively. In patients with no evidence of AKI, the mean urinary NGAL was not changing. In total, there was no association between urinary level of NGAL and the incidence of AKI after CABG (Table 4).

\section{Discussion}

Our findings showed that urinary NGAL level was not a reliable diagnostic or prognostic marker to diagnose or predict transient AKI associated with CABG within the first six hours after the procedure in adults.

Although urinary NGAL has been suggested as a promising biomarker for early diagnosis of AKI, some recent studies have suggested that this marker has only moderate diagnostic validity in patients undergoing cardiac surgery $(16,17)$. Parameters such as patient's age, serum creatinine level, ejection fraction and probably

Table 1. The mean serum creatinine levels in patients undergoing coronary artery bypass graft at baseline and different time-points post-surgery

\begin{tabular}{|c|c|c|c|c|c|}
\hline Time & Mean \pm SD & $\begin{array}{c}\text { Comparison with } \\
\text { preoperative serum } \\
\text { creatinine level }(\mathrm{mg} / \mathrm{dL}) \\
{[P \text { value }]}\end{array}$ & $\begin{array}{l}\text { Comparison with } \\
\text { peri- surgery serum } \\
\text { creatinine level }(\mathrm{mg} / \\
\mathrm{dL} \text { ) [ } P \text { value }]\end{array}$ & $\begin{array}{l}\text { Comparison with day } \\
1^{\text {st }} \text { serum creatinine } \\
\text { level }(\mathrm{mg} / \mathrm{dL})[P \\
\text { value }]\end{array}$ & $\begin{array}{l}\text { Comparison with day } \\
2^{\text {nd }} \text { serum creatinine } \\
\text { level }(\mathrm{mg} / \mathrm{dL})[P \text { value }]\end{array}$ \\
\hline Preoperative & $1.19 \pm 0.04$ & - & $0.05[1]$ & $-0.21[0.001]$ & $-0.06[1]$ \\
\hline Peri- surgery & $1.14 \pm 0.04$ & $-0.05[1]$ & - & $-0.26[0]$ & $-0.11[0.085]$ \\
\hline Day $1^{\text {st }}$ after surgery & $1.40 \pm 0.05$ & $0.21[0.001]$ & $0.26[0]$ & - & $0.15[0.040]$ \\
\hline Day $2^{\text {nd }}$ after surgery & $1.25 \pm 0.05$ & $0.06[1]$ & $0.11[0.08]$ & $-0.15[0.04]$ & - \\
\hline Day $3^{\text {rd }}$ after surgery & $1.17 \pm 0.05$ & $-0.01[1]$ & $-0.03[1]$ & $-0.022[0.002]$ & $-0.08[0.36]$ \\
\hline
\end{tabular}

Table 2. Comparison of urine neutrophil gelatinase-associated lipocalin at various time points between patients with and without acute kidney injury after coronary artery bypass graft

\begin{tabular}{|c|c|c|c|c|}
\hline \multirow{2}{*}{ Time points } & \multicolumn{3}{|c|}{ Urinary NGAL (ng/mL) } & \multirow[b]{2}{*}{$P$ value } \\
\hline & Patients with AKI (Mean \pm SD) & Patients without AKI (Mean \pm SD) & Total (Mean \pm SD) & \\
\hline Preoperative & $382.5 \pm 11.7$ & $391.3 \pm 40.5$ & $386.6 \pm 81.9$ & 0.812 \\
\hline 2 hours postoperative & $375.9 \pm 49.9$ & $377.3 \pm 67.3$ & $374.8 \pm 60.9$ & 0.951 \\
\hline 6 hours postoperative & $365.9 \pm 84.9$ & $356.9 \pm 84.8$ & $360.6 \pm 83.3$ & 0.789 \\
\hline
\end{tabular}

NGAL, Neutrophil gelatinase-associated lipocalin; AKI, acute kidney injury; SD, standard deviation.

Table 3. The association between elevated urinary NGAL at 2 and 6 hours after surgery and the incidence of acute kidney injury post coronary artery bypass graft

\begin{tabular}{|c|c|c|c|c|}
\hline Elevated urinary NGAL & $\begin{array}{c}\text { Patients with AKI } \\
\text { No. (\%) } \\
\end{array}$ & $\begin{array}{c}\text { Patients without AKI } \\
\text { No. (\%) }\end{array}$ & $\begin{array}{c}\text { Total } \\
\text { No. (\%) } \\
\end{array}$ & $P$ value \\
\hline 2 hours postoperative & $7(53.8)$ & $7(43.8)$ & $14(43.8)$ & 0.5 \\
\hline 6 hours postoperative & $5(45.5)$ & $5(31.3)$ & $10(37)$ & 0.4 \\
\hline
\end{tabular}


Table 4. The mean alternations of urinary NGAL in patients with and without acute kidney injury at 2 and 6 hours post coronary artery bypass graft

\begin{tabular}{lcc}
\hline Variations in urinary NGAL at different & \multicolumn{2}{c}{ Urinary NGAL $(\mathrm{ng} / \mathrm{mL})$} \\
\cline { 2 - 3 } time points respective to baseline & $\begin{array}{c}\text { Patients } \\
\text { (preoperative) }\end{array}$ & $\begin{array}{c}\text { Patients } \\
\text { without AKI }\end{array}$ \\
\hline 2 hours postoperative & $4.2 \pm 25.3$ & $2.2 \pm 22.1$ \\
6 hours postoperative & $2.8 \pm 34.9$ & $-7.9 \pm 22.7$ \\
\hline
\end{tabular}

other unknown mediators may influence the diagnostic accuracy of this marker in AKI associated with cardiac surgery. In the present study, our sample size was 29 which is comparable with some other studies on the subject (16). We assessed the diagnostic predictability of urinary NGAL concentration in adults within the first six hours after cardiac surgery. In other studies, different periods of time have been investigated in patients with different age spectrums. For example; one study showed that urinary NGAL was significantly increased in pediatric patients with AKI within 15 hours after cardiac surgery. In a recent report, urinary NGAL also correlated with surgical variables and clinical outcomes. In addition, the normalization of urinary NGAL respective to serum creatinine improved the validity of NGAL for predicting the severity of AKI; however, the diagnostic validity of this marker remained unclear (18). It seems that this biomarker delivers superior diagnostic applicability in younger patients; however, this needs to be further investigated.

Sargentini et al declared that urinary NGAL was able to detect AKI earlier than serum creatinine in adults undergoing cardiac surgery; nevertheless, the sensitivity and specificity of this marker were not superior compared with other biomarkers (19). Wagener et al also noted that urinary NGAL level significantly correlated with the duration of cardiopulmonary bypass and aortic crossclamp procedures; however, its prognostic value was limited in patients with AKI (20).

In the study by Wan et al, the incidence of AKI after cardiac surgery was reported as $27 \%$ (21). They found that the urinary level of NGAL and NGAL/creatinine ratio were strong and were the independent predictors of AKI at two hours post-cardiac surgery.

Our understanding regarding the role of urinary NGAL in the postoperative management of AKI is currently limited. Therefore, more studies are needed to ascertain the potential application of this marker in prevention and treatment of ischemia-reperfusion renal injury in this condition. Urinary NGAL has been able to effectively and independently predict the AKI after cardiopulmonary bypass.

\section{Conclusion}

Contrary to the previous studies, the present research showed no significant associations between urinary NGAL levels at neither two hours nor six hours of post-surgery and also the incidence of AKI. This finding suggested that urinary NGAL level is not an independent predictor of AKI post-CABG surgery. We, therefore, concluded that urinary NGAL level is an unreliable marker in predicting AKI post-CABG surgery.

\section{Recommendations}

It is suggested to interpret the urinary level of NGAL with respect to serum creatinine level. It is better to consider longer intervals to determine this parameter after surgery, and to incorporate patient's hydration and urine output to more precisely scrutinize the applicability of this biomarker in predicting AKI. In fact, hydration after cardiac surgery can dilute urine and reduce the urinary concentration of this biomarker. Furthermore, the ratio of urinary NGAL to either creatinine or total NGAL may be more reliable in this regard.

\section{Limitations of the study}

Our sample size was low, which limited the power of the study. We suggest investigating the urine NGAL levels in a large group of patients in future studies.

\section{Acknowledgments}

This study has been presented as a lecture at $15^{\text {th }}$ International Congress of Nephrology, Dialysis and Transplantation, on Mashhad (2015).

\section{Authors' contribution}

$\mathrm{AP}$ and $\mathrm{AB}$ designed the study. $\mathrm{AE}$ consulted on the procedure. HC contributed in clinical study. KK performed statistical analysis, $\mathrm{MH}$ and $\mathrm{AP}$, prepared the manuscript, since $\mathrm{MH}$ corresponded to the journal. All authors read and signed the final draft.

\section{Conflicts of interest}

The authors declare that the research was conducted in the absence of any commercial or financial relationships that could be construed as a potential conflict of interest.

\section{Ethical considerations}

Ethical issues (including plagiarism, data fabrication, double publication) have been completely observed by the authors.

\section{Funding/Support}

The Zanjan University of Medical Sciences supported this research financially (Grant \# A-11-627-3).

\section{References}

1. Albert MA, Antman EM. Preoperative evaluation for cardiac surgery. In: Cohn LH, Edmunds LH Jr, eds. Cardiac Surgery in the Adult. New York: McGraw-Hill, 2003. p. 23548.

2. Haase M, Haase-Fielitz A, Bagshaw SM, Ronco C, Bellomo R. Cardiopulmonary bypass-associated acute kidney injury: 
a pigment nephropathy? Contrib Nephrol. 2007;156:34053. doi: 10.1159/000102125

3. Lassning A, Schmidlin D, Mouhieddine M, Bachmann LM, Druml W, Bauer P, et al. Minimal changes of serum creatinine predict prognosis in patients after cardiothoracic surgery: a prospective cohort study. J Am Soc Nephrol. 2004;15:1597-605.

4. Mehta RH, Grab JD, O’Brien SM, Bridges CR, Gammie JS, Haan CK, et al. Bedside tool for predicting the risk of postoperative dialysis in patients undergoing cardiac surgery. Circulation 2006;114:2208-16. doi: 10.1161/ CIRCULATIONAHA.106.635573

5. Wijeysundera DN, Karkouti K, Dupuis JY, Rao V, Chan CT, Granton JT, et al. Derivation and validation of a simplified predictive index for renal replacement therapy after cardiac surgery. JAMA 2007;297:1801-9. doi: 10.1001/ jama.297.16.1801

6. Devarajan P. Update on mechanisms of ischemic acute kidney injury. J Am Soc Nephrol 2006;17:1503-20. doi: 10.1681/ASN.2006010017.

7. Jo SK, Rosner MH, Okusa MD. Pharmacologic treatment of acute kidney injury: Why drugs haven't worked and what is on the horizon. Clin J Am Soc Nephrol 2007;2:356-65. doi: 10.2215/CJN.03280906

8. Mishra J, Dent C, Tarabishi R, Mitsnefes MM, Ma Q, Kelly C, et al. Neutrophil gelatinase-associated lipocalin (NGAL) as a biomarker for acute renal injury after cardiac surgery. Lancet 2005;365:1231-38. doi: 10.1016/S01406736(05)74811-X.

9. Bellomo R, Ronco C, Kellum JA, Mehta RL, Palevsky P. Acute renal failure: Definition, outcome measures, animal models, fluid therapy and information technology needs. The Second International Consensus Conference of the Acute Dialysis Quality Initiative (ADQI) Group. Crit Care. 2004;8:R204-12. doi: $10.1186 /$ cc2872

10. Ramirez-Sandoval JC, Herrington W, MoralesBuenrostro LE. Neutrophil gelatinase-associated lipocalin in kidney transplantation: A review. Transplant Rev (Orlando)2015;29:139-44. doi: 10.1016/j.trre.2015.04.004.

11. Trachtman H, Christen E, Cnaan A, Patrick J, Mai V, Mishra J, et al. Urinary NGAL in D+HUS: A novel marker of renal injury. Pediatr Nephrol. 2006;21:989-49. doi: 10.1007/ s00467-006-0146-y
12. Buonafine M, Martinez-Martinez E, Jaisser F. More than a simple biomarker: the role of NGAL in cardiovascular and renal diseases. Clin Sci (Lond). 2018;132:909-923. doi: 10.1042/CS20171592.

13. Brunner HI, Mueller M, Rutherford C, Passo MH, Witte D, Grom A, et al. Urinary NGAL as a biomarker of nephritis in childhood-onset SLE. Arthritis Rheum. 2006;54:257784. doi: 10.1002/art.22008

14. Hirsch R, Dent C, Pfriem H, Allen J, Beekman RH, Ma Q, et al. NGAL is an early predictive biomarker of contrastinduced nephropathy in children. Pediatr Nephrol. 2007; 22:2089-95. doi: 10.1007/s00467-007-0601-4

15. Mishra J, Mori K, Ma Q, Kelly C, Yang J, Mitsnefes M. Amelioration of ischemic acute renal injury by NGAL. J Am Soc Nephrol. 2004;15:3073-82. doi: 10.1097/01. ASN.0000145013.44578.45.

16. Ho J, Tangri N, Komenda P, Kaushal A, Sood M, Brar R, et al. Urinary, plasma, and serum biomarkers' utility for predicting acute kidney injury associated with cardiac surgery in adults: a meta-analysis. Am J Kidney Dis. 2015; 66:993-1005. doi: 10.1053/j.ajkd.2015.06.018

17. Lee C-C, Chang C-H, Chen S-W, Fan P-C, Chang S-W, Chen Y-T, et al. Preoperative risk assessment improves biomarker detection for predicting acute kidney injury after cardiac surgery. PLoS One. 2018;13:e0203447. doi: 10.1371/journal.pone.0203447

18. Alcaraz AJ, Gil-Ruiz MA, Castillo A, López J, Romero C, Fernández SN et al. Postoperative neutrophil gelatinaseassociated lipocalin predicts acute kidney injury after pediatric cardiac surgery. Pediatr Crit Care Med. 2014;15:121-30. doi: 10.1097/PCC.0000000000000034

19. Sargentini V, Mariani P, M DA, Pistolesi V, Lauretta MP, Pacini F, et al. Assessment of NGAL as an early biomarker of acute kidney injuryin adult cardiac surgery patients. J Biol Regul Homeost Agents. 2012;26:485-93.

20. Wagener G, Gubitosa G, Wang S, Borregaard N, Kim M, Lee HT. Urinary neutrophil gelatinase-associated lipocalin and acute kidney injury after cardiac surgery. Am J Kidney Dis 2008;52:425-33. doi: 10.2215/CJN.04240609

21. Wan X, Cao CC, Chen Y, Xiao YL, Wu WF, Chen X, et al. Association between urinary neutrophil gelatinaseassociated lipocalin and acute kidney injury after cardiac surgery. Zhonghua Yi Xue Za Zhi 2008;88:1318-22.

Copyright (c) 2020 The Author(s); Published by Nickan Research Institute. This is an open-access article distributed under the terms of the Creative Commons Attribution License (http://creativecommons.org/licenses/by/4.0), which permits unrestricted use, distribution, and reproduction in any medium, provided the original work is properly cited. 